\title{
Phacoemulsification without preoperative mydriasis in patients with age-related cataract associated with type 2 diabetes
}

This article was published in the following Dove Press journal:

Clinical Ophthalmology

5 December 2016

Number of times this article has been viewed

Rajesh Subhash Joshi

Department of Ophthalmology, Vasantrao Naik Government Medical College, Yavatmal, India
Correspondence: Rajesh Subhash Joshi Department of Ophthalmology, Vasantrao Naik Government Medical College, Yavatmal-400000I, India Email jrajesh5@rediffmail.com
Aim: To study the effect of intracameral injection of preservative-free lignocaine to induce pupil dilatation, without using any preoperative dilating eyedrops or intraoperative mydriatics in patients with age-related cataract associated with type 2 diabetes mellitus.

Design: This was a prospective, observational, and interventional case series conducted at a tertiary eyecare center in rural India.

Materials and methods: A total of 32 patients underwent phacoemulsification under topical anesthesia for visually significant cataract. Preoperative pupillary diameter was measured 3 days prior to surgical procedure under mydriatics (tropicamide $0.8 \%$, phenylephrine hydrochloride $5 \%$ ). Intraoperative pupillary dilatation was achieved by $1 \%$ intracameral lignocaine solution alone. Effective phacoemulsification time (EPT), total surgical time, and final pupillary diameter were recorded at the conclusion of surgery.

Results: The average duration of diabetes was 11.2 (range 5-25) years. There was no difference in dilatation by preoperative pupil-dilating drops $(5.2 \pm 0.5 \mathrm{~mm}$, range $3-8.3 \mathrm{~mm})$ and intracameral $1 \%$ lignocaine during the surgical procedure $(P=0.63)$. There was a negative correlation $(r=-0.92)$ between diabetes duration and dilatation of pupils with dilating drops and intracameral lignocaine. The duration of the surgery, EPT, and phacoemulsification chop had statistically insignificant effects on mydriasis, while the grade of the nucleus had a statistically significant effect on mydriasis. Intracameral lignocaine had no significant effect on blood pressure or pulse. There were no surgical complications that could have compromised the visual outcome. None of the patients developed macular edema in a follow-up period of 3 months; 28 patients (87.5\%) had best-corrected visual acuity from $20 / 30$ to $20 / 20$.

Conclusion: Intracameral lignocaine $1 \%$ provides sufficient mydriasis for the safe phacoemulsification of cataract in patients with type 2 diabetes of variable duration.

Keywords: phacoemulsification, type 2 diabetes, intracameral lignocaine, topical anesthesia, intracameral mydriatic solution

\section{Introduction}

In recent times, there has been an increase in the number of people with diabetes. India currently has 62.4 million people with diabetes. ${ }^{1}$ By 2030, this number is expected to increase to over 100 million. $^{2}$ The majority of people with diabetes $(>90 \%)$ have type 2 diabetes. Type 2 diabetes predominantly affects older individuals in developed countries, but in developing nations it also affects the younger population. Therefore, the proportion of patients developing cataracts associated with diabetes will be on the rise. Diabetes influences lens transparency and pharmacological pupil dilatation. Duration and control of diabetes are important factors in cataract development. ${ }^{3-6}$ 
Cataracts occurring in diabetic patients can be due to the diabetes itself or due to an accelerated age-related cataract, in which case the cataracts occur earlier than normal. ${ }^{7}$ Developments in self-sealing clear corneal incision and topical anesthesia have made fast postoperative functional recovery possible. The challenges encountered by surgeons during phacoemulsification of diabetic cataracts include poor pupillary dilatation, capsulocortical and nuclear cortical adhesions leading to difficult hydroprocedure and nucleus rotation, the sticky and leathery nature of the nucleus, and pupillary constriction during the procedure. ${ }^{8-11}$

Phacoemulsification is the preferred method for the treatment of diabetic cataract. ${ }^{9-14}$ It minimally affects the bloodaqueous barrier, thus making it the procedure of choice. ${ }^{15}$ Topical anesthesia is the safe and effective alternative to peribulbar and retrobulbar anesthesia for phacoemulsification. ${ }^{16,17}$ Adequate mydriasis is a prerequisite for cataract surgery, which is achieved by repeated instillation of sympathomimetic and anticholinergic eyedrops. Systemic absorption of these drugs may lead to side effects, such as rise in blood pressure, which could be of great concern in patients with a cardiovascular disorder. Acute psychotic reactions have been observed after topical instillation of $1 \%$ cyclopentolate. ${ }^{18}$

Superior safety and efficacy of intracameral mydriatic solution (cyclopentolate $0.1 \%$ and phenylephrine $1.5 \%$ ) over topical mydriatic drops have been proved in various studies. ${ }^{19-21}$ However, intracameral mydriatic solution needs to be prepared from commercially available eyedrops before cataract surgery. Intracameral phenylephrine has a weaker mydriatic effect than topical mydriatics, rendering small pupillary size during cataract surgery.22 This may be disadvantageous in diabetic patients with cataract. The safety and efficacy of $1 \%$ intracameral lignocaine hydrochloride during routine phacoemulsification surgery have been shown in various studies. ${ }^{23-27}$ It not only produces a mydriatic effect but also causes anesthesia of the iris.

We evaluated the role of preservative-free intracameral $1 \%$ lignocaine in initiating and maintaining pupillary dilatation during phacoemulsification of diabetic cataract without the use of preoperative mydriatics or nonsteroidal anti-inflammatory drugs. Secondary aims were to see the effect of the chop technique, nucleus density, and the duration of diabetes on sustainability of mydriasis during the phacoemulsification.

\section{Materials and methods}

This prospective interventional case series comprised patients with visually significant cataracts and type 2 diabetes of variable duration scheduled for phacoemulsification and intraocular lens implantation. Preoperative examination was done 3 days before the scheduled phacoemulsification procedure. After dilatation of pupil (tropicamide $0.8 \%$ and phenylephrine hydrochloride 5\%), the patient was taken to the operation theater for measurement of pupillary size. A surgical caliper was used to measure the size of the pupil. The grade of cataract was determined with lens-opacity classification system III on slit lamp. ${ }^{28}$

Patients with pseudoexfoliation, subluxated lens, pupillary size of $4 \mathrm{~mm}$ and less after dilatation, postvitrectomized eyes, just one eye, and visible iris deformity were excluded from the study. Patients with intraoperative iris trauma and posterior capsular rupture were also excluded from the study. The ethical committee of Government Medical College and Hospital, Yavatmal, Maharashtra, India approved the study, and all patients signed an informed consent form to participate in the study.

\section{Surgical technique}

A single surgeon performed all surgeries. No preoperative mydriatic drops were used. Proparacaine hydrochloride 0.5\% (Paracain; Sunways Ltd, Mumbai, India) drops were instilled every 5 minutes, twice before the start of the surgery. Paracentesis incisions were performed as required. Preservative-free lignocaine (1\%, $0.3 \mathrm{~mL}$; Oculigno; Entod Pharmaceuticals, Mumbai, India) was injected into the anterior chamber. Trypan blue dye was injected under air to stain the anterior capsule. Capsulorhexis was achieved with Utrata forceps followed by hydrodissection. Phacoemulsification was accomplished in the capsular bag by the vertical chop technique (Galaxy Pro phacoemulsifier; Appasamy Associates, Chennai, India). ${ }^{29}$ Subsequently, cortical cleanup was completed, followed by implantation of a single-piece hydrophilic intraocular lens in the bag.

\section{Pupil-size measurement}

The horizontal diameter of the pupil was measured under an operating microscope with a caliper. The intensity of the microscope light was kept constant throughout the procedure. At 90 seconds after injection of $1 \%$ lignocaine in the anterior chamber, the horizontal diameter of the pupil was measured again. At the termination of the surgical procedure and after the wound-hydration diameter of the pupil was measured, the patient's comfort, painful intraoperative sensations perceived by the patient, supplemental anesthesia, complications, and surgeon discomfort were noted. The anesthetist also noted vital parameters and any intravenous drugs required.

\section{Statistical analysis}

Data were entered into an Excel spreadsheet (version 14.1.0; Microsoft Corporation, Redmond, WA, USA), and statistical 
analysis was performed with SPSS version 20.0 (IBM, Armonk, NY, USA). Student's $t$-test was used to compare mean values. Spearman's correlation coefficient was used to study various parameters in mydriasis.

\section{Results}

The study included 21 males and eleven females with a mean age of $54 \pm 3$ years. The average duration of diabetes was 11.2 (range 5-25) years. The average size of the pupil under microscopy without intracameral injection of $1 \%$ lignocaine was $2 \pm 0.5$ (range $1.5-3$ ) $\mathrm{mm}$. The average size of the pupil after intracameral injection of $1 \%$ lignocaine was $5 \pm 0.5$ (range 2.5-8.5), which took $90( \pm 0.9)$ seconds. At the end of the surgical procedure, the mean size of the pupil was $5.5 \pm 0.5$ (range $2.5-5.8) \mathrm{mm}(P=0.45)$. There was no difference in dilatation from preoperative dilating drops $(5.2 \pm 0.5 \mathrm{~mm}$, range $3-8.3 \mathrm{~mm})$ and intracameral $1 \%$ lignocaine during the surgical procedure $(P=0.63)$. There was a negative correlation ( $r=-0.92)$ between duration of diabetes and pupil dilatation of with dilating drops and intracameral lignocaine (Figure 1). With an increase in the duration of diabetes, there was a reduction in the size of the pupil. The average duration of the surgical procedure was $18( \pm 5.3)$ minutes, and the average effective phacoemulsification time was $38( \pm 15.11)$ seconds. The effect of various parameters on the pupil is depicted in Table 1.

Intracameral supplementation of adrenaline was necessitated in three patients, as the pupil became extremely small. In one patient, the pupil failed to dilate with adrenaline. A iris retractor was required for the expansion of the pupil. One patient became uncooperative during the surgery. Topical $0.5 \%$ proparacaine drops were instilled and $1 \mathrm{~mL}$ subconjunctival injection of $2 \%$ lignocaine hydrochloride was given.

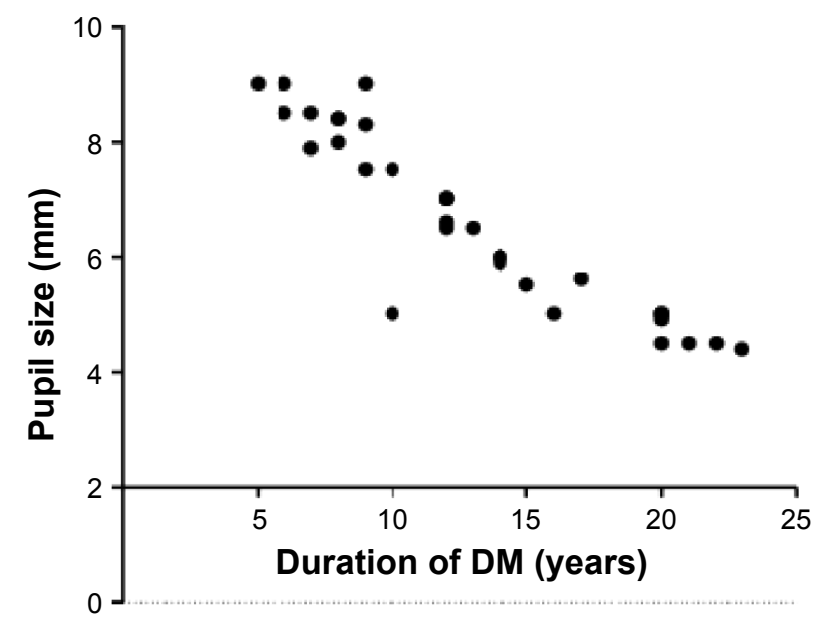

Figure I Correlation between duration of diabetes mellitus (DM) and pupil size.
Table I Effect of various parameters on intraoperative pupil size

\begin{tabular}{llll}
\hline Parameter & \multicolumn{2}{l}{$\begin{array}{l}\text { Spearman's } \\
\text { correlation coefficient }\end{array}$} & \multicolumn{2}{l}{$\boldsymbol{P}$-value } & Interpretation \\
\hline $\begin{array}{l}\text { Duration of } \\
\text { diabetes }\end{array}$ & 0.92 & 0.03 & Strong correlation \\
$\begin{array}{l}\text { Phaco chop } \\
\begin{array}{l}\text { Duration of } \\
\text { surgical procedure }\end{array}\end{array}$ & 0.93 & 0.12 & Weak correlation \\
$\begin{array}{l}\text { Effective } \\
\text { phaco time }\end{array}$ & 0.93 & 0.56 & Weak correlation \\
Grade of nucleus & 0.92 & 0.34 & Weak correlation \\
\hline
\end{tabular}

Abbreviation: Phaco, phacoemulsification.

The effect of mydriatic and intracameral lignocaine on blood pressure and pulse is illustrated in Table 2. Though there was an increase in blood pressure and pulse from baseline, it was not statistically significant after instillation of mydriatics. However, with intracameral lignocaine, there was no significant rise in blood pressure or pulse. There was no change in the parameters in patients requiring intracameral adrenaline. Oxygen saturation was maintained at $99 \%-100 \%$.

There were no surgical complications that could have compromised the visual outcome, and none of the patients had developed macular edema after a follow-up period of 3 months. A total of 28 patients $(87.5 \%)$ had best-corrected visual acuity from $20 / 30$ to $20 / 20$. Four patients $(12.5 \%)$ had visual acuity ranging from $20 / 60$ to $20 / 30$ due to disc pallor. None of the patients developed postoperative rise in intraocular pressure.

\section{Discussion}

Mydriasis before cataract surgery is achieved by repeated instillation of topical anticholinergic and sympathomimetic mydriatic agents, such as tropicamide $1 \%$, cyclopentolate $1 \%$, and phenylephrine $2.5 \%$ or $10 \%$. This increases the preoperative waiting period and has systemic and ocular adverse effects. ${ }^{18-23}$ Ocular surface problems are known in diabetic patients. ${ }^{30,31}$ The presence of preservatives in the formulations may precipitate surface ocular problems. To overcome these problems, $1 \%$ intracameral lignocaine, combined $0.5 \%$ lignocaine $+0.001 \%$ epinephrine, and intracameral mydriatic solution containing lignocaine and phenylephrine have been tried in routine cataract surgery for the initiation and maintenance of pupillary dilatation. ${ }^{18,19,30-34}$ Intracameral preservative-free lignocaine has been tried in routine cataract and trabeculectomy surgery to relieve pain and discomfort. ${ }^{35}$ Lincoff et al noted that mydriasis after accidental injection of lignocaine resulted in complete recovery of retinal functions after 4 hours and both retinal and pupillary function 
Table 2 Effect of mydriatic and intracameral lignocaine on blood pressure and pulse

\begin{tabular}{llll}
\hline Parameter & Baseline & $\begin{array}{l}\text { After instillation } \\
\text { of mydriatic drops }\end{array}$ & $\begin{array}{l}\text { Intraoperative under } \\
\text { intracameral lignocaine }\end{array}$ \\
\hline Blood pressure, & $\mathrm{S}=\mathrm{I} 33( \pm 5.2)$ & $\mathrm{S}=\mathrm{I} 42( \pm 2 . \mathrm{I})$ & $\mathrm{S}=\mathrm{I} 38( \pm \mathrm{I} . \mathrm{I})$ \\
$\mathrm{mmHg}(\mathrm{SD})$ & $\mathrm{D}=70( \pm 3.4)$ & $\mathrm{D}=74( \pm \mathrm{I} .3)$ & $\mathrm{D}=72( \pm \mathrm{I})$ \\
Pulse, bpm (SD) & $78( \pm 9.3)$ & $86( \pm 3)$ & $80( \pm 2)$ \\
\hline
\end{tabular}

Abbreviations: bpm, beats per minute; SD, standard deviation; S, systolic; D, diastolic.

by 16 hours..$^{36}$ The safety of intracameral lignocaine on the endothelium has been shown in various studies..$^{24,37,38}$ It has been shown by Iradier et al that it does not cause inflammation of ocular tissues on intraocular use. ${ }^{27}$ None of the patients in our study developed corneal complications in the form of prolonged corneal edema or decompensation.

Nikeghbali et al studied the role of intracameral lignocaine in cataract surgery. ${ }^{23}$ However, only four patients with diabetes were included, and the duration of diabetes was not mentioned in the study. This study shows that phacoemulsification can be performed safely with intracameral injection of $1 \%$ preservative-free lignocaine without preoperative instillation of mydriatics in diabetic patients with variable duration. Preoperative mydriatic instillation and intracameral injection of lignocaine have the same dilating effect. Average pupillary size was $5 \mathrm{~mm}$ with preoperative mydriatics and intracameral lignocaine, suggesting that mydriatics can be avoided preoperatively. The pupillary size noted by Nikeghbali et al after intracameral injection of lignocaine was $7.1 \mathrm{~mm} .{ }^{23}$ The pupillary size noted by Gupta et al was $6.9 \mathrm{~mm}$ with $0.5 \%$ lignocaine and $0.001 \%$ epinephrine in routine cataract surgery. ${ }^{33} \mathrm{We}$ did not use epinephrine in irrigating solution. Three patients needed intracameral epinephrine during the surgical procedure, as pupils became small. Bozkurt et al have shown that intracameral injection of $0.2 \mathrm{~mL}$ epinephrine $(1: 5,000)$ did not increase the risk of central macular edema in eyes with no risk factors that had uneventful phacoemulsification with intraocular lens implantation..$^{39}$ However, patients with diabetes are prone to the development of macular edema postoperatively with the use of epinephrine..$^{40,41}$ None of the patients in our study had developed macular edema at the 3-month follow-up.

Autonomic dysfunction in diabetes has been shown to cause small pupils and reduced dilatation with mydriatics. ${ }^{42}$ We have noted a negative correlation between the duration of diabetes and pupil size. The same was applicable to the intracameral lignocaine. A number of previous studies have noted that patients with a long duration of diabetes have small pupils and that there is a statistically significant association between small pupils and the severity of diabetes. ${ }^{43-45}$
The average duration of diabetes in our study was 11.2 years. With an increase in the duration of diabetes, there are likely chances of pupils remaining small throughout the surgical procedure. Pupil expanders may prove to be helpful in such a situation. One patient needed a pupil-expanding device, as the pupil failed to dilate with epinephrine. The anesthetic effect of lignocaine prevents pain during pupillary stretching.

The average surgical time in our study was 18 minutes, which is more than that of the studies by Nikeghbali et al, Gupta et al, and Joshi et al. ${ }^{23,29,33}$ The average surgical time noted by Joshi et al in age-related cataract was $6.913 \pm 4.45$ minutes, wherein patients with nondilating pupils and diabetic cataracts were excluded. We could not compare our surgical time, as there is no literature available on the use of only intracameral lignocaine in patients with cataract with type 2 diabetes. The lower surgical times in Nikeghbali et $\mathrm{a}^{23}$ (11.67 \pm 3.05 minutes) and Gupta et $\mathrm{a}^{33}$ (13 minutes) could have been due to the inclusion of nondiabetic patients and the use of epinephrine in the irrigation. The extended surgical time in our study could have been related to peculiarities in cataract associated with diabetes of longer duration. The presence of corticocapsular adhesions makes hydrodissection and subsequent cortical aspiration difficult. We followed a quick-chop technique for nucleus division. However, a sticky and leathery nucleus makes the division of the nucleus incomplete. This required separation of tenacious nuclear fibers with Sinskey hook. This helped in the reduction of effective phacoemulsification time. Another reason could be the slow dilating effect of lignocaine. It took an average of 90 seconds to dilate pupils to the level of preoperative mydriatics.

None of the patients developed glaucoma postoperatively. With the hard, tenacious fibers of diabetic cataract, the phacoemulsification energy used to separate and emulsify the fragments is more than that for routine cataract. We used a Sinskey hook to separate the fragments. This reduced total energy used.

Visual outcome was not compromised: 28 (87.5\%) patients had best-corrected visual acuity from 20/30 to 20/20. This correlates with Lundberg and Behndig's findings. ${ }^{19}$ The safety of intracameral lignocaine was also proved by 
the fact that no remarkable rise of pulse and blood pressure was observed throughout the surgical procedure. None of the patients developed surgical complications that could have compromised the surgical outcome.

There are a few limitations to this study, predominantly the lack of a control arm using intracameral mydriatic solution or epinephrine in the irrigation. However, the study intended to validate the use of intracameral lignocaine, rather than a comparison with the various formulations. We did not consider the magnification factor of the cornea while calculating actual pupillary diameter. However, a similar method was followed in all patients. The study was carried out at a single center and a single surgeon was involved, which omits the comparison in skills and surgical techniques. Maintenance of pupillary dilatation postsurgery was beyond the scope of the study.

\section{Conclusion}

Intracameral lignocaine is a safe and efficient alternative to traditional topical and intracameral mydriatics during phacoemulsification surgery in patients with cataracts and type 2 diabetes of variable duration. Though local mydriatics are available cheaply, the use of a preoperative intracameral dilating solution before cataract surgery avoids the preoperative waiting period, surface ocular problems as intracameral mydriatics are preservative free, systemic rise of blood pressure and precipitation of cardiovascular problems known with diabetics.

\section{Acknowledgment}

The author acknowledges Dr Sonal Muley, resident ophthalmologist, Vasantrao Naik Government Medical College, Yavatmal, India for her contribution toward preoperative and intraoperative assessment during the study period.

\section{Disclosure}

The author reports no conflicts of interest in this work.

\section{References}

1. Anjana RM, Pradeepa R, Deepa M, et al. Prevalence of diabetes and prediabetes (impaired fasting glucose or/and impaired glucose tolerance) in rural and urban India: phase 1 results of the Indian Council of Medical Research - India Diabetes (INDIAB) study. Diabetologia. 2011; 54:3022-3027.

2. International Diabetes Federation. IDF Diabetes Atlas. 5th ed. Brussels: IDF; 2011.

3. Ginter E, Simko V. Global prevalence and future of diabetes mellitus. Adv Exp Med Biol. 2012;771:35-41.

4. Bron AJ, Brown NA, Harding JJ, Ganea E. The lens and cataract in diabetes. Int Ophthalmol Clin. 1998;38:37-67.

5. Shrestha RK. Ocular manifestations in diabetes, a hospital based prospective study. Nepal Med Coll J. 2011;13:254-256.
6. Adeoti $\mathrm{C}$, Isawumi M, Ashaye A, Olomola B. The anterior segment of the eye in diabetes. Clin Ophthalmol. 2012;6:667-671.

7. Mechini U, Cappelli S, Virgili G. Cataract surgery and diabetic retinopathy. Semin Ophthalmol. 2003;18:103-108.

8. Khokhar S, Pangtey MS, Soni A. Surgical peculiarities in type II diabetic cataracts during phacoemulsification. Ophthalmic Surg Lasers Imaging. 2003;34:100-103.

9. Zaczek A, Zetterström C. Cataract surgery and pupil size in patients with diabetes mellitus. Acta Ophthalmol Scand. 1997;75:429-432.

10. Ostri C, Lund-Andersen H, Sander B, La Cour M. Phacoemulsification cataract surgery in a large cohort of diabetes patients: visual acuity outcomes and prognostic factors. J Cataract Refract Surg. 2011; 37:2006-2012.

11. Zarnowski T, Machowicz-Matejko E, Zagórski Z. [Anterior chamber inflammation following cataract surgery in patients with noninsulin-dependent diabetes mellitus]. Klin Oczna. 2002;104:354-356. Polish.

12. Gatinel D, Lebrun T, Le Toumelin P, Chaine G. Aqueous flare induced by heparin-surface-modified poly(methyl methacrylate) and acrylic lenses implanted through the same-size incision in patients with diabetes. J Cataract Refract Surg. 2001;27:855-860.

13. Zaczek A, Zetterström C. Posterior capsule opacification after phacoemulsification in patients with diabetes mellitus. J Cataract Refract Surg. 1999;25:233-237.

14. Aslan BS, Müftüoglu O, Gayretli D. Crater-and-split technique for phacoemulsification: modification of the crater-and-chop technique. $J$ Cataract Refract Surg. 2012;38:1526-1530.

15. Liu Y, Luo L, He M, Liu X. Disorders of the blood-aqueous barrier after phacoemulsification in diabetic patients. Eye (Lond). 2004;18: 900-904.

16. Fichman RA. Use of topical anesthesia alone in cataract surgery. J Cataract Refract Surg. 1996;22:612-614.

17. Patel BC, Burns TA, Crandall A, et al. A comparison of topical and retrobulbar anesthesia for cataract surgery. Ophthalmology. 1996;103: 1196-1203.

18. Mirshahi A, Kohnen T. Acute psychotic reaction caused by topical cyclopentolate use for cycloplegic refraction before refractive surgery: case report and review of the literature. J Cataract Refract Surg. 2003; 29:1026-1030.

19. Lundberg B, Behndig A. Intracameral mydriatics in phacoemulsification cataract surgery. J Cataract Refract Surg. 2003;29:2366-2371.

20. Liou SW, Yang CY. The effect of intracameral adrenaline infusion on pupil size, pulse rate, and blood pressure during phacoemulsification. J Ocul Pharmacol Ther. 1998;14:357-361.

21. Morgado G, Barros P, Martins J, Lima A, Martins N. Comparative study of mydriasis in cataract surgery: topical versus Mydriasert versus intracameral mydriasis in cataract surgery. Eur J Ophthalmol. 2010;20: 989-993.

22. Lundberg B, Behndig A. The mydriatic effect of intracameral epinine hydrochloride. Invest Ophthalmol Vis Sci. 2009;50:5336-5338.

23. Nikeghbali A, Falavarjani KG, Kheirkhah A. Pupil dilation with intracameral lidocaine during phacoemulsification: benefits for the patient and surgeon. Indian J Ophthalmol. 2008;56:63-64.

24. Weller A, Pham DT, Häberle H. [Intracameral anesthesia with lidocaine in cornea guttata]. Ophthalmologe. 2002;99:29-31. German.

25. Garcia A, Loureiro F, Limao A, Sampaio A, Ilharco J. Preservativefree lidocaine $1 \%$ anterior chamber irrigation as an adjunct to topical anesthesia. J Cataract Refract Surg. 1998;24:403-406.

26. Eggeling P, Pleyer U, Hartmann C, Rieck PW. Corneal endothelial toxicity of different lidocaine concentrations. $J$ Cataract Refract Surg. 2000;26:1403-1408.

27. Iradier MT, Fernandez C, Bohorquez P, Moreno E, del Castillo JB, Garcia J. Intraocular lidocaine in phacoemulsification: an endothelium and blood-aqueous barrier permeability study. Ophthalmology. 2000; 107:896-901.

28. Chylack LT Jr, Wolfe JK, Singer DM, et al. The lens opacities classification system III. Arch Ophthalmol. 1993;111:831-836. 
29. Joshi RS. A single drop of $0.5 \%$ proparacaine hydrochloride for uncomplicated clear corneal phacoemulsification. Middle East Afr J Ophthalmol. 2013;20:221-224.

30. Kaji Y. Prevention of diabetic keratopathy. Br J Ophthalmol. 2005;89: 254-255.

31. Sun H, Mi X, Gao N, Yan C, Yu FS. Hyperglycemia-suppressed expression of Serpine1 contributes to delayed epithelial wound healing in diabetic mouse corneas. Invest Ophthalmol Vis Sci. 2015;56: 3383-3392.

32. Cionni RJ, Barros MG, Kaufman AH, Osher RH. Cataract surgery without preoperative eyedrops. J Cataract Refract Surg. 2003;29: 2281-2283.

33. Gupta SK, Kumar A, Agarwal S, Agarwal S. Phacoemulsification without preoperative topical mydriatics: induction and sustainability of mydriasis with intracameral mydriatic solution. Indian J Ophthalmol. 2014;62:333-336

34. Behndig A, Eriksson A. Evaluation of surgical performance with intracameral mydriatics in phacoemulsification surgery. Acta Ophthalmol Scand. 2004;82:144-147.

35. Joshi RS. Proparacaine hydrochloride topical drop and intracameral $0.5 \%$ lignocaine for phacotrabeculectomy in patients with primary open angle glaucoma. Middle East Afr J Ophthalmol. 2014;21:210-215.

36. Lincoff $\mathrm{H}, \mathrm{Z}$ weifach $\mathrm{P}$, Brodie $\mathrm{S}$, et al. Intraocular injection of lidocaine. Ophthalmology. 1985;92:1587-1591.

37. Lai JS, Tham CC, Lam DS. Intracameral lidocaine in trabeculectomy: a preliminary safety and efficacy study. Indian J Ophthalmol. 2002;50: 197-200.
38. Eggeling P, Pleyer U, Hartmann C, Rieck PW. Corneal endothelial toxicity of different lidocaine concentrations. $J$ Cataract Refract Surg. 2000;26:1403-1408.

39. Bozkurt E, Yazici AT, Pekel G, et al. Effect of intracameral epinephrine use on macular thickness after uneventful phacoemulsification. J Cataract Refract Surg. 2010;36:1380-1384.

40. Neto CA, Júnior CA, Moreira AT. Optical coherence tomography in patients undergoing cataract surgery. Arq Bras Oftalmol. 2015;78: 241-245.

41. Makri OE, Georgalas I, Georgakopoulos CD. Drug-induced macular edema. Drugs. 2013;73:789-802.

42. Karavanaki K, Davies AG, Hunt LP, Morgan MH, Baum JD. Pupil size in diabetes. Arch Dis Child. 1994;71:511-515.

43. Bremner FD, Smith SE. Pupil abnormalities in selected autonomic neuropathies. J Neuroophthalmol. 2006;26:209-219.

44. Kwon HJ, Kim HY. A pharmacologic pupillary test in the diagnosis of diabetic autonomic neuropathy. Korean J Ophthalmol. 2009;23: 291-295.

45. Straub RH, Thies U, Jeron A, Palitzsch KD, Schölmerich J. Valid parameters for investigation of the pupillary light reflex in normal and diabetic subjects shown by factor analysis and partial correlation. Diabetologia. 1994;37:414-419.
Clinical Ophthalmology

\section{Publish your work in this journal}

Clinical Ophthalmology is an international, peer-reviewed journal covering all subspecialties within ophthalmology. Key topics include: Optometry; Visual science; Pharmacology and drug therapy in eye diseases; Basic Sciences; Primary and Secondary eye care; Patient Safety and Quality of Care Improvements. This journal is indexed on

\section{Dovepress}

PubMed Central and CAS, and is the official journal of The Society of Clinical Ophthalmology (SCO). The manuscript management system is completely online and includes a very quick and fair peer-review system, which is all easy to use. Visit http://www.dovepress.com/ testimonials.php to read real quotes from published authors. 